\title{
Optimization of Nanoemulsion in Chemix 7.00 Program : Using Isopropyl Myristate as Oil Phase
}

\author{
Nur Alam Abdullah ${ }^{1}$, Mahdi Jufri $^{2 *}$, Abdul Mun'im ${ }^{3}$, Fadlina Chany Saputri ${ }^{4}$ \\ \{aldan80kurniawan@gmail.com ${ }^{1,}$ mahdi.jufri@farmasi.ui.ac.id ${ }^{2}, \underline{\text { munim@farmasi.ui.ac.id }}{ }^{3}$, \\ fadlina.chany@farmasi.ui.ac.id $\left.{ }^{4}\right\}$ \\ *corresponding author
}

Fakultas Farmasi Universitas Indonesia ${ }^{1,2,3,4}$

\begin{abstract}
This research is the development of nanoemulsion base preparation by applying a ternary diagram system using Chemix 7.00. This study aims to see the advantages of the Chemix 7.00 series program in determining the focus area for nanoemulsion in a mixture of oil phase (Isopropyl Myristate), smix (tween 80 and propylene glycol), and water at various ratios from 1 to 9 and 9 to 1 part. This research applies the high energy method with Ultra Turrax High Share Homogenization (HSH) at a speed of 20,000 rpm 15 minutes to form a nanoemulsion. All formulas were evaluated with the Chemix 7.00 program to see which formulas form a stable nanoemulsion area according to the standard criteria for nanoemulsion preparations in general. The result was 45 nanoemulsion bases were obtained. The use of the Chemix 7.00 ternary diagram yields 14 bases forming a nanoemulsion area with an average particle size of below 500 $\mathrm{nm}$. Among the 14 formulas, there is 1 formula bases that are stable and meets the standard of nanoemulsion research, namely the nanoemulsion base with a ratio of 4.45 .50 (oil, smix, water) with a particle size of $185.7 \mathrm{~nm}$ each, zeta - 28.2, PDI 0,2 mV, D90 measuring $120 \mathrm{~nm}$ and the TEM morphology is quite round. Determination of the nanoemulsion base area using the Chemix series 7.00 program is quite helpful in data processing so that optimal research results are obtained.
\end{abstract}

Keywords: Chemix 7.00, isopropyl Myristate (IPM), nanoemulsion, particle size.

\section{Introduction}

In the development of nanoemulsion preparations, 3 methods can be selected to formulate various types of active substances. The three methods are the titration method, low energy, and high energy. Nanoemulsion is known as a pharmaceutical preparation for dispersing colloid oil in water $(\mathrm{O} / \mathrm{W})$ or water in oil $(\mathrm{W} / \mathrm{O})$, which is formed in the presence of surfactants and cosurfactants and has a particle size of $1-100 \mathrm{~nm} \mathrm{[1].}$

Several research results concluded that there were 3 methods in the stages of making nanoemulsion preparations. The three parts are respectively the titration method, the low energy method, and the high energy method. The low energy method consists of PIT (Phase inversion temperature) and SNEDDS (Self nanoemulsion drug delivery system). Meanwhile, high energy consists of High Share Homogenization (HSH), Ultrasonication, (HPH) High-Pressure Homogenization, and microfluidization [2].

For this reason, the choice of developing a nanoemulsion base is needed so that the data obtained can be processed as effectively and efficiently as possible. An active compound, both 
polar and non-polar, can be easily mixed in the nanoemulsion base, which has been stabilized by applying these three methods. In terms of determining stable and good nanoemulsion areas, a computerized digital program device is needed to carry out experimental data processing. The pseudo ternary model or known as the ternary triangle is a program introduced by Chemix School.com. In determining the nanoemulsion area, all the results of experiments carried out with each component comparison of the constituent compounds should be processed with this program in a computerized manner and not manually ternary [3].

Chemix 7.00 is a paid chemistry program and can be found easily online. The ternary triangle system can be used to compile the nanoemulsion preparation results from various experiments that have been carried out to find stable and good nanoemulsion areas, the arrangement can be manual or automatic, such as the 7.00 series chemix program used in this study. This program is very good and helps in determining the area ofnanoemulsion that has been formed so that the best formula can easily be selected. For this reason, this study aims to see the extent to which the Chemix 7.00 series program can be used as a medium in helping process experimental data on the development of colloid dispersing liquid in the form of nanoemulsions by finding or determining the area of stable and good nanoemulsion so as to facilitate and assist the research process that can be used and save research time. The effectiveness and efficiency in constructing a pseudo ternary triangle diagram using the 7.00 series chemix program represents an advance in digital technology [4]

\section{Methods and materials}

The tools used are glass tools as needed, Ultra Turrax 1000 x T25 Digital IKA ${ }$, Marvern ${ }^{\circledR}$ PSA (particle size analyzer), TEM JOUL ${ }^{\circledR}$. Materials in the form of isopropyl myristate (IPM) oil phase, aqua distillate water phase, Tween 80 as a surfactant, propylene glycol as a cosurfactant. We used the nanoemulsions method of high energy sharing high homogenization device (HPH) at a speed of 20,000 rpm for 15 minutes.

\subsection{Construction of Pseudo Ternary Phase Diagram}

Each base formula is made based on the ratio value between the oil phase and the smix phase (a mixture of 1:9 to 9: 1 surfactant and cosurfactant) and aquadestillata as a predetermined water phase, the amount of each is $50 \mathrm{ml}, 60 \mathrm{ml}, 70 \mathrm{ml}$, , $80 \mathrm{ml}$, and $90 \mathrm{ml}$ [5].

\subsection{Evaluation and Characterization of Base Preparations}

All experimental results were examined such as particle size, polydispersity index value, zeta potential. Organoleptic, $\mathrm{pH}$, and viscosity tests, morphology. To determine the nanoemulsion area as needed, data processing was carried out and analyzed using the Chemix 7.00 program to obtain the nanoemulsion area [6], [7]. [8] 


\section{Results}

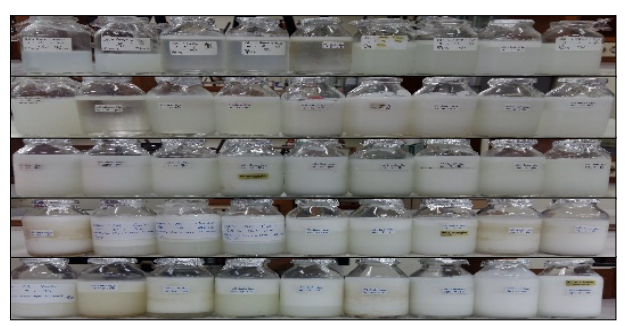

Fig. 1. 45 Results of a nanoemulsion based formulation experiment

There are 4 nanoemulsion bases that have a particle size $<200 \pm 2 \mathrm{~nm}$ at the comparison value of each ternary diagram, namely Water: Smix: IPM 50: 5: 45, 60:16:24, 60: 12:28, 60: 8:32, obtained the smallest particle size $185.7 \pm 2 \mathrm{~nm}$ in the formula 50: 5: 45 (water: smix: IPM) [10].

The results of the viscosity test followed the non-newton law with values reaching $20 \mathrm{Cp}$ and $24 \mathrm{Cp}$. Meanwhile, the results of the morphological structure examination, only the selected formula was carried out by TEM (transmission electron microscopy) examination. Figure 3 shows that the size of the nanoemulsion-based globule with the IPM oil phase is quite close to spherical or spherical, with an average particle size of $< \pm 200 \mathrm{~nm}$. Then the zeta value obtained for testing the preparation parameters is $-28.2 \mathrm{mV}$. This shows that the resistance strength to withstand the cohesion between globules is good enough so that the risk of incorporation in nanoemulsion preparations can be avoided [9].

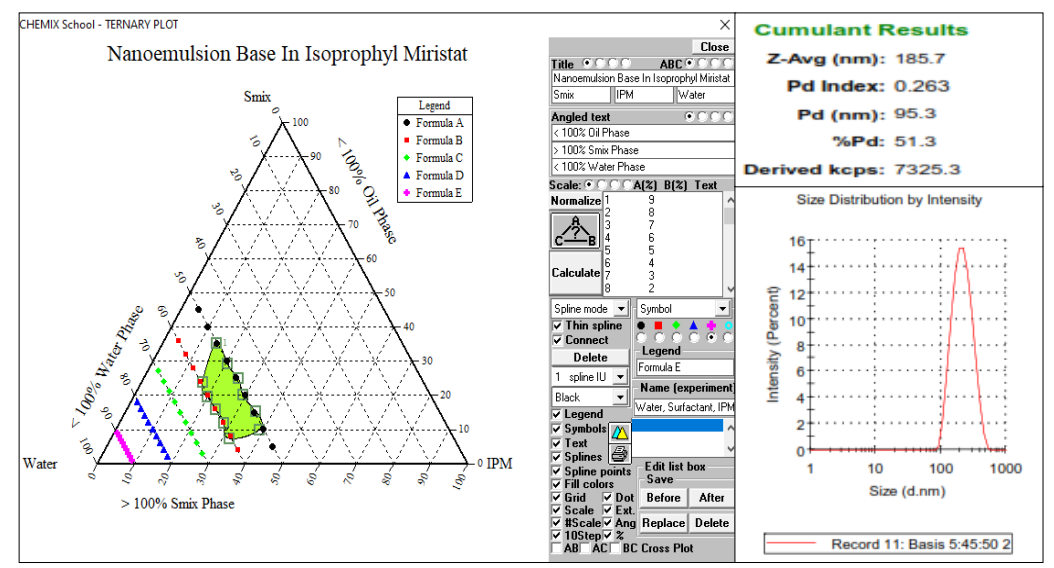

Fig. 2. Chemix program version 7.00 


\section{Discussion}

From the results of this study, 45 base formulas (see figure 1) were obtained which were made with the high energy method using the High Share Homogenization (HPH) device at a speed of 20,000 rpm for 15 minutes for each formula made. Of the 45 above, the average physical form of the preparation was seen as opaque or emulsion and some were transparent. Whereas in the translucent physical form, there are five best base formulas, and of the five, there is one nanoemulsion based formula that is the best, namely the base 50: 45: 5 (water: smix: IPM). In another study, it was found that by using IPM as the basis for nanoemulsion preparations, there was an 11-fold increase in the effectiveness of the IPM flux in the in vitro transdermal test 18 . So this research shows quite good results with the suitability of previous studies involving IPM as the oil phase in nanoemulsion preparations [10], [11]

The ternary diagram study has assisted many pharmaceutical researchers in developing preparations involving water oil. Homogeneous mixing of the oil phase and the water phase with the help of a surfactant. The existence of an emulsifier or better known as an emulator/surfactant which is assembled based on a predetermined ratio value and is expected to form a stable nanoemulsion preparation, which is also durable during storage. The four basic formulas are arranged into a ternary diagram system to see which formulas show the formation of nanoemulsion preparations. Based on the literature, the ideal nanoemulsion preparation is a translucent physical appearance, with a particle size of $<500 \mathrm{~nm}, \mathrm{D} 90 \pm 200 \mathrm{~nm}$, a PDI value of $0.1-0.3$, and zeta potential of $\pm 30 \mathrm{mV}[12]$

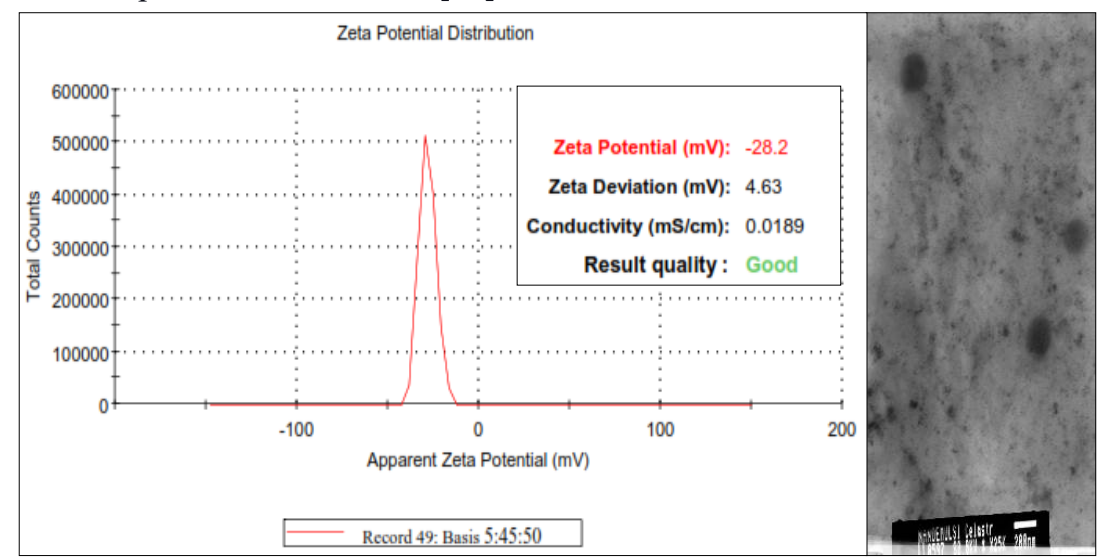

Fig.3. Potential zeta and morphological structure

Several studies on colloid-based delivery systems, often yielding a large number of experimental results. so that all of this data if simulated or compiled manually based on particle size will find difficult, and it is quite difficult for researchers to compile the desired ternary diagram system, as a result, it will take a lot of time and the risk of human error easily occurs, in the end, the nanoemulsion area is formed or it is less efficient and effective. The ternary triangle program already exists in various computer applications that are known today, for example using .exe and/or word on office computers, however, from the research results, only a few researchers use this method because the way it is used requires certain techniques and tends to the results which are not optimal. There are also other programs known as automated programs such as the prosim and chemix series. In several published journals there are 
researchers who use both programs and the results are very good in visualizing. For this reason, in this study, only the Chemix 7.00 series program was used to assist in processing experimental titration data for nanoemulsion preparations to be arranged into a ternary system in order to find and determine the nanoemulsion area formed based on the similarity of evaluation results on the nanoparticle colloid requirement system [13], [14]

In Figure 2. for the Chemix 7.00 series program, how to operate it is not too difficult, even very easy to understand even for novice users. Because this chemix program is actually a paid chemical system program so getting this program doesn't require a complicated method, just download it on the website provided and do a paid activation so that the program can be used. In the Chemix program, the 7.00 series are not much different from the previous series because the results obtained are still satisfying to its users. This program is not only intended to create colloid ternary systems but can also be used for various chemical mixtures that are physically difficult to mix or form a single or two-phase system so that the colloid system is used in this program. The advantage of this chemix program is that there is no need to calculate manual comparisons anymore because the system created by this program will automatically generate its own comparative value or figure. For each base, Nanoemulsion with the obtained particle size, the chemix program is considered a point and will be linked to other dots based on similar particle sizes. With these points the analysis can be carried out to draw lines that have a close relationship with each point. The intersecting lines will form a certain area and this is called a nanoemulsion area based on the similarity of particle size [15], [16].

\section{Conclusion}

Determination of the nanoemulsion base area using the Chemix series 7.00 program is quite helpful in data processing so that optimal research results are obtained.

\section{Conflict of Interest}

The authors declared that they have no conflict of interest.

\section{Acknowledgment}

The authors gratefully acknowledge to Directorate of Research and Community Engagements of Universitas Indonesia for financial support: Hibah No: NKB0200/UN2.R3.1/HKP.05.00/2019.

\section{Reference}

[1] Singh Y, Meher J G, Raval K, Khan F A, Chaurasia M, Jain N K and Chourasia M K. Nanoemulsion: Concepts, development and applications in drug delivery J. Control. Release. pp. 252 28-49 (2017)

[2] Patel R B, Patel M R, Thakore S D and Patel B G. Nanoemulsion as a Valuable Nanostructure Platform for Pharmaceutical Drug Delivery (Elsevier Inc.). (2017)

[3] Lala R R and Awari N G. Nanoemulsion-based gel formulations of COX-2 inhibitors for enhanced efficacy in inflammatory conditions Appl. Nanosci. pp. 143-51 (2014)

[4] Aqil M, Kamran M, Ahad A and Sarim S. Development of clove oil based nanoemulsion of olmesartan for transdermal delivery: Box - Behnken design optimization and pharmacokinetic evaluation J. Mol. Liq. pp. 238-48 (2016) 
[5] Sun H, Liu K, Liu W, Wang W, Guo C, Tang B, Gu J, Zhang J, Li H, Mao X, Zou Q and Zeng H. Development and characterization of a novel nanoemulsion drug-delivery system for potential application in oral delivery of protein drugs Int. J. Nanomedicine. pp. 5529-4. (2012)

[6] Miastkowska M, Sikora E, Ogonowski J, Zielina M and Łudzik A. The kinetic study of isotretinoin release from nanoemulsion Colloids Surfaces A Physicochem. Eng. Asp. pp. 63-8 (2016)

[7] Morsy M A, Abdel-Latif R G, Nair A B, Venugopala K N, Ahmed A F, Elsewedy H S and Shehata T M Preparation and evaluation of atorvastatin-loaded nanoemulgel on wound-healing efficacy Pharmaceutics. pp. 1-15. (2019)

[8] Rocha-Filho P, Ferrari M, Maruno M, Souza O and Gumiero V. In Vitro and In Vivo Evaluation of Nanoemulsion Containing Vegetable Extracts Cosmetics.pp. 32 (2017)

[9] Klang V, Matsko N B, Valenta C and Hofer F. Electron microscopy of nanoemulsions: An essential tool for characterisation and stability assessment Micron. pp. 85-103 (2012)

[10] Azeem A, Rizwan M, Ahmad F J, Iqbal Z, Khar R K, Aqil M and Talegaonkar S. Nanoemulsion Components Screening and Selection: a Technical Note AAPS PharmSciTech. pp. 69-76 (2009)

[11] Arellano A, Santoyo S, Martín C and Ygartua P. Influence of propylene glycol and isopropyl myristate on the in vitro percutaneous penetration of diclofenac sodium from carbopol gels Eur. J. Pharm. Sci. pp. 129-35 (1999)

[12] Saka H. Ternary Phase Diagram Introd. to Phase Diagrams Mater. Sci. Eng. pp. 121-69. (2020)

[13] Labege Cedex ProSim Ternary Diagram. pp. 15

[14] Jadhav C, Kate V and Payghan S A. Investigation of effect of non-ionic surfactant on preparation of griseofulvin non-aqueous nanoemulsion J. Nanostructure Chem. pp. 107-13 (2015)

[15] Mustafa A, Eid M, Elmarzugi N A L I and El-enshasy H A L I. Preparation And Evaluation Of Olive Oil Nanoemulsion Using Sucrose Monoester. pp. 3-9 (2013)

[16] Anon Chemix-chemistry-software.com. (2019) 